\title{
Complete dentures: an introduction
}

\author{
J. F. McCord, ${ }^{1}$ and A. A. Grant, ${ }^{2}$
}

\section{This introductory article sets the scene for a series of articles on complete denture prosthodontics.}

\section{In this part, we will}

\section{discuss:}

- Changes in the levels of edentulousness

- Changes in the degree of complexity of treatment of edentulous patients

- Changes in how prosthodontics is reported in professional journals.

\footnotetext{
${ }^{*}$ Head of the Unit of Prosthodontics,

${ }^{2}$ Emeritus Professor of Restorative

Dentistry, University Dental Hospital

of Manchester, Higher Cambridge Street, Manchester M156FH

${ }^{*}$ Correspondence to: Prof. J. F. McCord

email:Learj@fs1.den.man.ac.uk

REFEREED PAPER

(c) British Dental Journal

2000; 188: 373-374
}

$\mathrm{T}$ he purpose of this series is to reflect current changes in philosophy towards the prescription of complete dentures. To achieve these aims, this series will deal with trends in edentulousness and changes in perceptions to edentulousness to the treatment modalities in complete denture provision.

This series is not intended to replace standard textbooks of prosthodontics, but rather to serve as a chairside guide/aide-mémoire of clinical procedures for the general dental practitioner with an interest in complete denture therapy. The balance of emphasis in this series has been determined by the experience gained in dealing with difficulties acknowledged by practitioners and patient indictment of treatment they have received.

Over the past 30 years, surveys of adult dental health indicate that the prevalence of people, in developing countries, becoming edentulous is decreasing. ${ }^{1}$ The figures for England and Wales covering 1968 to 1988 are presented in Table 1.

In the United Kingdom as a whole, the overall percentage of adults who were edentulous fell from $30 \%$ in 1978 to $21 \%$ in $1988 .{ }^{1}$ A parallel study spanning 1985-1986 in the United States reported that $41 \%$ of adults over the age of 65 were edentulous. ${ }^{2}$ According to Winkler in $1977,{ }^{3}$ almost $50 \%$ of the 22.6 million edentulous Americans were 65 years of age or older. In parallel with this is the almost $50 \%$ drop in the number of complete upper and complete lower dentures $(\mathrm{C} / \mathrm{C})$ and relines provided under General Dental Service (GDS) regulations between 1970 and 1990 (Table 2). This table also indicates the relative percentages of the total cost to the (dental) budget. ${ }^{4}$

Although these statements are factually correct, they must be balanced, in the United Kingdom at least, by two separate factors. First of all, a significant number of general dental practitioners have become independent practitioners, thus disengaging themselves from National Health Service regulations, therefore many dentures provided will be unrecorded.

A second, and professionally important, factor is the finding that many (edentulous) patients when examined on routine dental visits, require replacement dentures (normative need) although they themselves did not feel this need (perceived view). This indicates the potential for a possibly large reservoir of unmet need in the population, in general, and in the edentulous elderly population in particular.

Clearly, although the (edentulous) percentage of the adult population is estimated to continue to decrease into the next century, the provision of replacement complete dentures to those currently edentulous will present a considerable task to the dental profession in the United Kingdom. ${ }^{5}$

Two factors adding to the relative complexity of this task are:

i) The reduction in teaching of prosthodontic technology and in decreased minimum requirements of completed cases during undergraduate curricula. This means that new graduates are potentially less able to provide a satisfactory prosthodontic service.

ii) Those patients who are edentulous are becoming more clinically demanding either because of oral conditions present at the time of total tooth loss or the deterioration of anatomical, physiological and sometimes psychological well-being which often are sequelae of edentulousness.

For these reasons, a sound biological approach to complete denture construction is necessary and, although this will be emphasised

Table 1 Percentoges of adult edentulous patients in England and Wales, 1968-1988 
in the next three parts, the dental practitioner must be aware of the scientific basis of complete denture construction. This is of very real relevance in the United Kingdom, where the dental practitioner, at present, is the sole licensed agent to undertake clinical prosthodontic treatment for a patient. Practitioners should be familiar with the technical aspects of complete denture construction in order that they may direct the fabrication of the prostheses for which they are clinically and legally responsible. Failure to communicate clearly with a dental technician cannot facilitate a harmonious prosthodontic team. The latter should be built out of mutual respect between clinician, nurse, technician and patient.

Recent laboratory-based studies have indicated that there would appear to be an increasing trend towards the dental profession not fulfilling their responsibility to technical colleagues who have received little or no training in relevant clinical sciences. ${ }^{6-8}$ Although two of these studies relate to removable partial dentures, they nevertheless reflect a trend for clinicians to abdicate their responsibilities in the prescription of a medical device.

While no apology should be made for an early reference to the biological basis of prosthodontics, due emphasis should be given to altering trends towards edentulousness among the population. Anecdotal and anamnastic comments among those already edentulous reflect perceptions that there was an inevitability of edentulousness. ${ }^{9}$ These perceptions were particularly prevalent among the working classes, especially in the north of Britain.

According to Todd and Lader, ${ }^{1}$ there were interesting variations in perceptions towards edentulousness among dentate adults wearing partial dentures and among dentate adults who did not have a partial denture and these are listed in Table 3.

While dental health education must be credited with reduced levels of edentulousness among the population in general, the expansion of dental information in newspapers and magazines has made the general public aware of the very real benefits of dental implants. Unfortunately, many patients do not satisfy the clinical criteria for the provision of implant-retained/supported prostheses. Those patients who are deemed unsuitable for implants, for whatever reason, will doubtless develop a negative stereotype towards conventional complete dentures and these negative stereotypes may make a successful outcome of treatment doubtful.

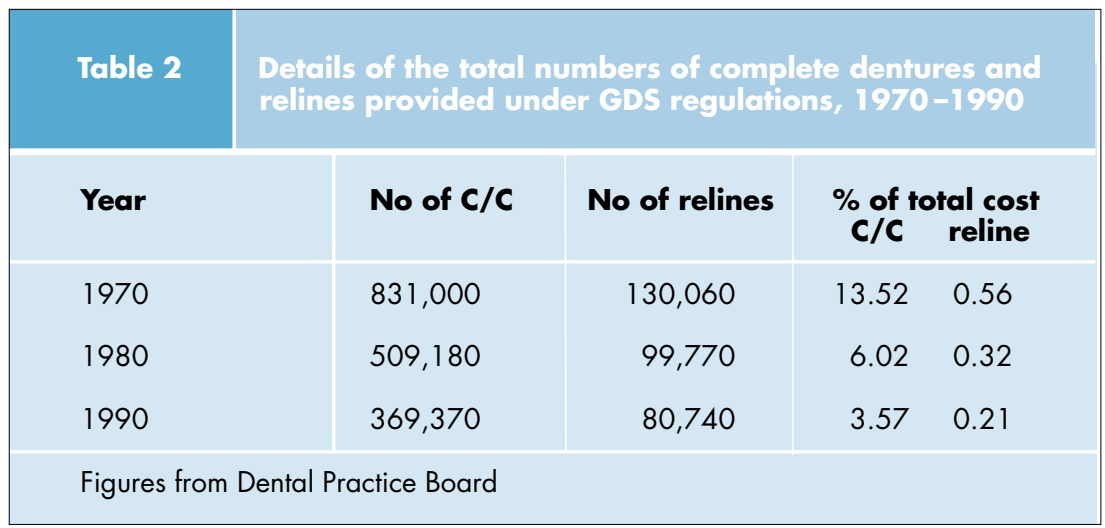

\begin{tabular}{|c|c|c|c|c|}
\hline Table 3 & \multicolumn{4}{|c|}{ Perceptions of dentate adults to edentulousness } \\
\hline Perception & \multicolumn{2}{|c|}{$\begin{array}{l}\text { Dentate and no RPD } \\
1978 \quad 1988\end{array}$} & \multicolumn{2}{|c|}{$\begin{array}{c}\text { Dentate and with RPD } \\
1978 \quad 1988\end{array}$} \\
\hline Very upsetting & $53 \%$ & $63 \%$ & $34 \%$ & $39 \%$ \\
\hline Slightly upsetting & $24 \%$ & $24 \%$ & $29 \%$ & $28 \%$ \\
\hline Not upsetting & $23 \%$ & $14 \%$ & $27 \%$ & $34 \%$ \\
\hline
\end{tabular}

A final aspect of perceptions towards complete dentures lies among the profession. For the purposes of this series, a survey of articles on complete denture prosthodontics in three journals (British Dental Journal, Journal of the American Dental Association and Journal of Prosthetic Dentistry) indicated that, in comparison to 30 years ago, the percentage of prosthodontic articles had fallen from almost $30 \%$ to less than $10 \%$.

Clearly this cannot be a facile comparison, as journals should reflect alterations in trends of treatment, and the developments during the past 20 years of adhesive techniques have significantly altered treatment trends. Concomitant with the reduction in (complete denture) prosthodontic publications is the risk that younger practitioners may be deprived of the opportunity to become acquainted with prosthodontic techniques beyond conventional undergraduate curricula.

Such a situation cannot be in the best interests of those requiring prosthodontic treatment and the purpose of this series is to serve as a convenient chairside guide for practitioners undertaking prosthodontic treatment. As this series is meant to supplement standard textbooks of prosthodontics, references will be used to enforce specific areas and to refer readers to key areas of general and prosthodontic literature.
1 Todd J, Lader D. Adult Dental Health, United Kingdom, 1988. London: OPCS, HMSO, 1991.

2 US Dept. of Health and Social Services. Oral Health of United States Adults. National Findings. NIH Publication No. 87. 2868. 1987.

3 Winkler S. Symposium on Complete Dentures. Dent Clin NAm 1977; 21 : 197-198.

4 Dental Practice Board (Eastbourne ): Personal Communication.

5 McCord J F, Grant A A, Quayle A A. Treatment options for the edentulous mandible. Eur J Prosthodont Rest Dent 1992; 1: 19-23.

6 Basker R M, Harrison A, Davenport J D, Marshall J L. Partial designs in general dental practice -10 years on. Br Dent J 1988; 165: 245-249.

7 Walter J D. A study of partial denture design produced by an alumni group of dentists in health service practice. 135-139.

8 Basker R M, Ogden A R, Ralph J P. audit of performance. Br Dent $J$ 1993; 174: 278-284.

9 Fish E W. The Englishman's teeth. $\mathrm{Br}$ Dent J 1942; 72: 129-138. Eur J Prosthodont Rest Dent 1995; 3: Complete denture prescription — an 